\title{
Melioidosis - A Serious Emerging Threat in Bangladesh
}

\author{
APARNA DAS, ${ }^{1}$ HAM NAZMUL AHASAN, ${ }^{2}$ BAHARUL MINNAT, ${ }^{3}$ CHAYAN KUMAR SINGHA ${ }^{4}$
}

\begin{abstract}
Melioidosis, a pyogenic infection that presents acutely or as a chronic infection, is caused by the soilassociated bacterium Burkholderiapseudomallei. Infection is acquired by inoculation or inhalation and is more common in patients with underlying chronic disease. It is endemic in the tropical belt. Although Bangladesh is not considered as a country where melioidosis is endemic, an increasing number of cases have been reported recently. Definitive diagnosis requires the isolation of $\mathrm{B}$. pseudomalleiin culture from clinical specimens. However, the laboratory diagnosis of melioidosis in Bangladesh and other under-resourced countries is limited by a lack of familiarity with the bacterium and a lack of facilities to accurately confirm the identity of the isolate. It is highly likely that melioidosis is underdiagnosed in this country. There is a need to increase awareness of this infection among clinicians and clinical microbiologists and improve laboratory facilities for the selective isolation and accurate identification of B. pseudomallei. Melioidosis has a notoriously protracted course; cure is difficult without a prolonged course of appropriate antibiotics.
\end{abstract}

Key words: Melioidosis, Burkholderiapseudomallei, Infection

\section{Background}

Melioidosisis a collective term for infection caused by the soil organism Burkholderiapseudomallei. The causative organism was first described by Whitmore in 1912 when hefirst isolated $B$. pseudomalleifrom an opiate addict in Rangoon. ${ }^{1}$ Whitmore's name was for some time eponymously linked with the disease melioidosis. So,name meloidosis, also known as Whitemore disease, is taken from 'melis' meaning 'distemper of asses' and 'eidos' meaning resembles 'glanders' 2 . For many years the causative organism of melioidosis was classified within the Pseudomonasgenus; however, in 1992,along with P. mallei and four other species, P. pseudomalleiwas reclassified to a new genus named after the USmicrobiologist Walter Burkholder. The genus Burkholderiacomprises at least 12 species, many of which are natural inhabitants of the rhizosphere, the bacteriological and chemical milieu of plant $\operatorname{roots}^{3}$.B. pseudomalleihas been classified by the Centers for Disease Control and Prevention as a category B bioterrorism agent, resulting in increased research and understanding of melioidosis ${ }^{4}$. The first case of human

1. Asstt. Prof. Dept. of Medicine, Dhaka Medical College \& Hospital.

2. Professor\& Head, Dept. of Medicine, Dhaka Medical College \& Hospital.

3. FlatNo.3-B,House No.47, Road No. 5, Dhanmondi R/ A, Dhaka.

4. Medical Officer, Dept. of Medicine, BangabandhuSheikh MujibMedical University.

Correspondence: Dr. Aparna Das,Asst. Prof., Dept. of Medicine, Dhaka Medical College \& Hospital. Mob:01914978719 melioidosis in Bangladesh was described in a diabetic adult in 2001. Since 2001, 5 cases of meloidosis were diagnosed in Ibrahim Medical College. All are diabetic and hailing from Mynensing,Tangail and Gazipur. Recently, scientist found this organism in the soil of gazipurfor the first time in Bangladesh $^{5}$. Therefore, Melioidosis is an uncommon but maybe fatal tropicaland emerging infectious diseasein Bangladesh. Its true prevalence however is not known, as there is under-reporting of its incidence due to the poorly understood disease process and misdiagnosis. At the same time enough resources are not always available in some areas to carry out research and increase the awareness of the general public and to educate and familiarize the medical profession about the disease. So, by this article, we try to increase the awareness about this disease among physicians.

\section{What is its Spectrum?}

The geographic area of the prevalence of the organism is bound to increase as the awareness increases. This disease has emerged over the past 25 years as an important cause of morbidity and mortality in Southeast Asia and northern Australia, and is also endemic in other tropical regions ${ }^{6}$. Melioidosis occurs predominantly in Southeast Asia, northern Australia, South Asia (including India), and China ${ }^{7-}$ 12. The majority of diagnosed cases are from Thailand ${ }^{13-}$ ${ }^{16}$.Malaysia ${ }^{17-20}$,Singapore ${ }^{21-27}$ and northern Australia ${ }^{28-}$

${ }^{30}$.Cases are also reported from Papua New Guinea ${ }^{31}$ and New Caledonia ${ }^{32}$.Northeastern Thailand and parts of northern Australia are "hyperendemic" for melioidosis 14,28 with seasonal peaks in the wet seasons. In 2010, there was been an increase in incidence in both northeast Thailand 
and northern Australia as well as in south Asia ${ }^{33-35}$ In Thailand 2000 to 3000 new cases are diagnosed every year. ${ }^{36}$ In Malaysia, reported seroprevalence in healthy individuals is $17-22 \%$ in farmers ( mainly rice farmers)and $26 \%$ in blood donors. ${ }^{37}$ In North Australia 0.6 to $16 \%$ of children have evidence of infection by B. pseudomallei ${ }^{28}$

Melioidosis has been described outside the classic endemic regions. Most of such cases are acquired by visitors to endemic areas, with symptoms arising later following departure from the endemic area. However, sporadic human or animal cases and occasional environmental isolates of $B$. pseudomallei have been described from Africa, Indian Ocean countries (such as Mauritius), the Middle East, the Caribbean, and Central and South America ${ }^{38-40}$ Some of these reports represent incorrect species diagnosis, but others have been confirmed as $B$. pseudomallei, making the endemic boundaries of melioidosis less clear ${ }^{10-12}$.

The B. pseudomallei have also been isolated in America. There are reports ofseveral cases of patients with melioidosis who have immigrated into Europe and the disease has been increasingly recognized in returning travellers to Europe from endemic areas. ${ }^{41}$ Two cases of melioidosis were reported in 2005 from southern Florida; both patients likely had separate exposure in Honduras ${ }^{42}$ Melioidosis is rare in the United States, with about five cases reported annually. ${ }^{43-46}$

Melioidosis is an emerging infection in India, with a reported prevalence of $7 \% .{ }^{47}$ Sri Lanka, positioned between $5-10^{0} \mathrm{~N}$, is situated in the endemic belt and has similarities in weather and environmental conditions with these countries. However Sri Lanka has been considered non-endemic for melioidosis. ${ }^{48}$

Melioidosis affects all ages but peak incidence is mainly between 40 to 60 years of age, with male to female ratio of $1.4: 1 .{ }^{49}$ There is a good correlation between the isolation of the organism from soil and the seroprevalence of antibodies in the population living in that region.

\section{What is B. pseudomallei?}

B. pseudomallei is agram negative intracellular organism, natural inhabitant of soil and water in the tropics and subtropics but can also survive in dry atmospheric conditions. It is ubiquitous in the rice-farming areas. It is also present in rubber plantations, cleared fields, cultivated and irrigated agricultural sites as well as drains and ditches. When isolated from blood, sputum, pus and other body fluids, B. pseudomalleiappears like safety pins (bipolar) under the microscope with methylene blue stain. It grows aerobically on ordinary media at $37^{\circ} \mathrm{C}$. Colonies are wrinkled and show dry daisy-head appearance along with a distinct odour. Mucoid colonies suggest that the patient is receiving antibiotic therapy.

B. psen pmallei can survive anaerobic conditions in the presenc of acidic environment, and also su five in distilled water for several years. ${ }^{50}$. The bacterium is resistant to penicillin, aminoglycosides, rifamycins and relatively insensitive to quinolones and macrolides. Therefore the therapeutic options are limited and continuous presence of the organism in patients is not fully understood. ${ }^{51,52} \mathrm{~B}$. pseudomalleiis resistant to macrolide and aminoglycoside antibiotics via a multidrug efflux pump. Mutations within the conserved motifs of the beta-lactamase enzyme ( enzyme that hydrolyses the cyclic amide bond of beta-lactam antibiotics )also account for the resistance patterns. ${ }^{53}$

\section{How does it transmit?}

There are several established modes of transmission within the patient population. The possible modes are inhalation, ingestion or inoculation through the skin lesions from the contaminated soil. ${ }^{54}$ Person-to-person transmission of $B$. pseudomallei especially between patient and his sibling or one of their playmates is common. ${ }^{55}$ Vertical transmission(from mother to child) is possible. ${ }^{56}$ It can also be transmitted by direct contact with infected rodents or infected food, soil, water, excreta; person-to-person transmission is also possible through use of injection needle. B. pseudomallei can also be transmitted through sexual intercourse. ${ }^{57}$ The link between melioidosis and consumption of Kava (Piper methysticum) has also been seen. ${ }^{57}$ Heavy rains and winds may cause increased inhalation of $B$. pseudomallei . Interestingly, a container of commercial handwash detergent was a source of infection in Northern Australia. ${ }^{29}$

\section{How does the disease occur?}

B. pseudomallei attack several eukaryotic cell lines. In both phagocytic and nonphagocytic cell lines, it can escape from the specialisedendocytic vacuoles into the cytoplasm to form actin-associated membrane protrusion that is thought to contribute to cell-to-cell spreading in the infected individuals. $58,59.60$ Capsule and a type III secretion system (TTSSexpressed mainly by pathogenic bacteria that is used to introduce deleterious proteins called effectors into host cells )facilitate $B$. pseudomallei to survive, escape from endocytic vesicles, facilitate bacterial invasion of epithelial cells and intracellular survival. ${ }^{61,62}$ The uptake of $B$. pseudomallei by several cell lines in culture leads to induction of cell fusion and formation of a multinucleated large cell. ${ }^{65}$ Production of nitric oxide has bactericidal activity and failure of infected cells to successfully control the growth and subsequent survival of intracellular $B$. pseudomallei are due to the suppression of inducible nitric oxide synthase (iNOS ) by $B$. pseudomallei . ${ }^{63,64}$ However, interferons enhance antimicrobial activity of macrophage infected $B$. pseudomallei by up-regulating iNOS. ${ }^{65}$,

\section{Who are at risk?}

Diabetis mellitus, Excessive alcohol consumption, Chronic renal impairment, Cystic fibrosis, Chronic heart failure, Chronic 
pulmonary disease,Leukaemia, lymphoma, Corticosteroid therapy, Immunodeficiency, Neoplasm and Kava Consumption $^{12}$.

\section{What are the clinical manifestations?}

It is important to note that melioidosis has a wide range of signs and symptoms that can be mistaken for other diseases such as tuberculosis or more common forms of pneumonia.Clinical manifestations of melioidosis range from localised infection to acute pneumonia and fulminant septic melioidosis. ${ }^{66,67,68}$ B. pseudomallei can cause disease in apparently healthy individuals . Once infected, it may remain dormant and become active after months, years or decades when host is immunocompromised. The factors that provoke the reactivation of latent pathogen probably are environmental variables, stress and immunity status. ${ }^{69,70}$ Localized melioidosis occurs in the form of acute suppurative lesions, superficial and deep-seated abscess in the psoas muscle, parotid glands and at the root of mesentery. ${ }^{71,72}$ It may also present as cellulitis, chronic otitis media and sepsis after burns and trauma. ${ }^{73,74,}$ The other manifestations are mycoticaneurysm, pericarditis, osteomyelitis epididymoorchitis and prostatitis. ${ }^{75,76,77}$ Melioidosis is also associated with systemic lupus erythematosus. ${ }^{78}$ Melioidotic prostatic abscesses are reported very rarely and are not easy to diagnose. In endemic areas, the elderly diabetic person who presents with high-grade fever and urinary obstruction may have $B$. pseudomalleiin the prostate gland ${ }^{79}$.Central nervous system involvement including brain abscess is a rare complication with high mortality. ${ }^{80,81}$ The immunesuppressed patients present with melioidosis septicaemia and their clinical features are similar to other gram-negative septicaemias and its prognosis is poor.

\section{How does it investigated?}

The diagnosis of acute or chronic melioidosis remains challenging. In endemic areas, melioidosis should be considered in the differential diagnosis of any Pyrexia of Unknown Origin (PUO), acute respiratory distress syndrome (ARDS) and acute septicaemia. The other conditions that melioidosis may present as are pneumonia, acute suppurative lesions, chronic granulomatous lesions, septic arthritis, osteomyelitis, epididymorchitis and mycotic aneurysm as well as radiological pattern of tuberculosis on the chest X-ray but not supplemented with mycobacterium tuberculosis positive sputum culture. In melioidosis, laboratory diagnosis is essential for successful patient management. C-reactive protein (CRP), an early indicator of infectious or inflammatory conditions may be elevated in melioidosis; however under normal CRP levels, melioidosis should not be ruled out. ${ }^{82}$

\section{Identification of $B$. pseudomallei}

Isolation of $B$. pseudomalleiby culture from a clinical specimen [blood, urine, sputum, skin lesions and swab samples from throat] is the gold standard of diagnosis. ${ }^{83}$ Correct identification of B. pseudomalleiis essential for long term supportive therapy in the treatment of melioidosis. A few simple tests can be employed to identify B. pseudomalleiin the endemic areas. These tests include positive oxidase test, bipolar gram staining, metallic sheen colonies on special media (Ashdown media which contains various dyes and gentamicin) and resistance to aminoglycosides. ${ }^{84}$

Conventional biochemical tests and API20E substrateutilization test panel [bioMérieux] kit is used for identification

\begin{tabular}{ll}
\hline Affected organ systems & Clinical manifestations \\
\hline Cardiovascular & Pericarditis, Pericardial effusion, Endocarditis, Endartitritis, \\
CNS & Meningitis( Primary), Encephalitis, Intracranial abscess \\
Genitourinary & $\begin{array}{l}\text { Urinary Tract infection, (Pyelonephritis), Prostatitis,Prostatic abscess, Epididimitis, Perinephric } \\
\text { abscess,Scrotal abscess, }\end{array}$ \\
Lymphatic & Lymphadenitis or abscess, \\
Hepatobiliary & liver abscess, Splenic abscess, Chalangitis, pancreatic abscess \\
Respiratory & Pneumonitis, Lung abscess, pleural effusion,Empyema, Miliary granuloma \\
Skeletal & Septic arthritis, Osteomyelitis, Subperiosteal abscess. \\
Skin and soft tissue & Cellulitis, Subcutaneous abscess, Infected wound, Chronic granuloma, Ecthyemaagangrenosum, \\
& Haemorrhageic bleb, Chronic pustules, Pyomiositis, urticaria, mastitis. \\
Others & Prolong pyrexia without obvious source. Septicemia, ophthalmitis, parotid abscess, corneal ulcer \\
\hline
\end{tabular}


of B. pseudomallei; however, it can easily misidentify Chromobacteriumviolaceum $i>C$. violaceum ). In one study, polymerase chain reaction (PCR) results showed that isolated $C$. violaceumhavesimilar repetitive extragenicpallindromic sequence (REPS) pattern with $B$. pseudomallei 85

In laboratory culture of $B$. pseudomallei, growth of other organisms may result in false negative result. This problem could be resolved using Ashdown's selective medium, which contains dyes, gentamicin and Trypticase peptone. ${ }^{86}$ Recently, more improved B. pseudomallei selective agars (BPSA) have been developed to improve the recovery of $B$. pseudomallei.$^{87}$

\section{Serological tests}

Serological tests are helpful in making a provisional diagnosis in the absence of isolation of $B$. pseudomallei in the specimen. Culture and serological methods are cost-effective and simple to perform but require experience to interpret results. Slide agglutination test results in rapid identification of $B$. pseudomallei. Indirect haemagglutination test is simple to perform as it detects the antibody against $B$. pseudomallei that appears in the blood within 1-2 weeks after the infection and reach maximal titre in 4 to 5 months. ${ }^{88}$ However its interpretation may be difficult because of the following points;

- False positive results due to cross-reaction with other gram negative bacteria which shares antigens (lipopolysaccharide of cell wall) particularly Burkholderiacepeciaand Legionella species.
- There may be rare false negative results

- High antibody titre may persist for a long time after infection subsides.

Enzyme linked immunosorbent assay (ELISA)test detects specific IgG and IgM antibodies of $B$. pseudomallei in serum specimens. ELISA is more convincing in terms of sensitivity and specificity for antibody detection as it points to an active disease process. ${ }^{89}$ The indirect ELISA is easy to perform and hence is recommended as a diagnostic serological test when melioidosis is in the differential diagnosis of PUO cases. Immunoflurorescent Antibody Assay is a rapid, highly sensitive and specific test for the identification of current infection.

\section{Molecular identification techniques}

Molecular biology techniques such as polymerase chain reaction (PCR), dot immunoassay, pulsed field gel electrophoresis (PFGE), restricted fragmentation length polymorphism (RFLP) and random amplification of particle of deoxyribonulease (RAPD) are also used for diagnosis. These are the recommended techniques for the rapid diagnosis of the disease and for monitoring therapy and epidemiological studies because of its high sensitivity, specificity, simplicity and speed. In recent times sensitive PCR amplification techniques for detecting the DNA of $B$. pseudomallei in clinical specimens, especially buffy coat specimens of acute melioidosis patients have been useful. ${ }^{90,91}$

Laboratory diagnostic approach

\begin{tabular}{|c|c|c|c|c|}
\hline $\begin{array}{l}\text { Clinical laboratory } \\
\text { results }\end{array}$ & $\begin{array}{l}\text { Isolation of } B . \\
\text { pseudomallei }\end{array}$ & $\begin{array}{l}\text { Identification } \text { of } B . \\
\text { pseudomallei }\end{array}$ & Serological tests & $\begin{array}{l}\text { Molecular methods to } \\
\operatorname{detect} B \text {. pseudomallei / } \\
D N A\end{array}$ \\
\hline \#Raised C RP & $\begin{array}{l}\text { \#Growth in } \\
\text { metallic sheen } \\
\text { colonies on } \\
\text { Ashdown's } \\
\text { selective medium }\end{array}$ & \#Positive oxydasetest & $\begin{array}{l}\text { \#Enzyme linked } \\
\text { immunosorbantassay(ELI } \\
\text { SA) to dect IgM\& IgG } \\
\text { antibodies. }\end{array}$ & \# PCR, \\
\hline \#Leukocytosis & & $\begin{array}{l}\text { \#Bipolar staining of } \\
\text { gram negative rods, } \\
\text { resistance } \\
\text { aminoglycosides. }\end{array}$ & $\begin{array}{l}\text { \#Indirrecthaemoagglutinat } \\
\text { ion test to dect antibodies } \\
\text { against B. pseudomallei }\end{array}$ & \#Dot Immunoassay. \\
\hline $\begin{array}{l}\text { \#In Diabetic Patients, } \\
\text { High level of glucose } \\
\text { in blood, high urea, } \\
\text { creatinine and } \\
\text { Glycosylated } \\
\text { haemoglobin. }\end{array}$ & & $\begin{array}{l}\text { \#Coventional } \\
\text { biochemical tests. } \\
\text { API20NE, API20E }\end{array}$ & $\begin{array}{l}\text { \#Immunofluroscent } \\
\text { Antibody assay }\end{array}$ & $\begin{array}{l}\text { \#PFGE,RFLP, } \\
\text { RAPD }\end{array}$ \\
\hline
\end{tabular}




\section{How it is treated?}

The main objective of treatment is to reduce the mortality and morbidity in melioidosis. Before the advent of proper antimicrobials, the mortality of the melioidosis patients used to be around $95 \%$. Rational use of antimicrobials has reduced it to half.B. pseudomalleiis inherently resistant to penicillin, ampicillin, first-generation and second-generation cephalosporins, gentamicin, tobramycin, streptomycin, and polymyxin. Of the newer antibiotics, ertapenem, tigecycline, and moxifloxacin have limited in vitro activity against clinical isolates of B. pseudomallei, and the minimum inhibitory concentration for doripenem is similar to that for meropenem. ${ }^{92}$ Various mechanisms of acquired antibiotic resistance have been identified, including efflux pumps, enzymatic inactivation, bacterial-cell-membrane impermeability, alterations in the antibiotic target site, and amino acid changes in pen $A$, the gene encoding the highly conserved class A â-lactamase. ${ }^{93,94}$

\section{Treatment is divided into intravenous and oral phases.}

Initial parenteral therapy is given for 10-14days or until clinical response is seen (whichever is the longer). Ceftazidime or a carbapenem antibiotic is the treatment of choice. Ceftazidime is used as first-line therapy in Thailand, with a switch to acarbapenem antibiotic in the event of treatment failure on ceftazidime. Parenteral treatment at the Royal Darwin Hospital, Australia (which sees the highest number of cases in Australia) consists of ceftazidime,or meropenem plus G-CSF if the patient has septic shock. ${ }^{95}$

The use of G-CSF in patients with severe melioidosis in Thailand is not supported by published evidence. ${ }^{96}$ The results of an ongoing randomized trial of ceftazidime versus meropenem for the treatment of melioidosis in Thailand will not be available for several years. The routine addition of TMP-SMX to ceftazidime or meropenem during the initial intensive therapy phase was discontinued in $2005 .{ }^{97} \mathrm{TMP}-\mathrm{SMX}$ is usually used in Australia for patients with neurological or prostatic melioidosis in view of its excellent penetration, the evidence for which is based on expert opinion and case series. ${ }^{98}$
Intravenous amoxicillin-clavulanic acid (AMC) is second-line empiric treatment. The switch from parenteral to oral antimicrobial therapy is made once the patient shows clear evidence of clinical improvement, including an absence of fever for $48 \mathrm{~h}$ and negative repeat blood culture taken at around 1 week after the onset of therapy. Prolonged parenteral therapy may be required for patients with disseminated infection, involvement of the central nervous system, bone or joint, and patients with deep-seated abscesses that cannot be drained.

Oral therapy consists of TMP-SMX alone (Australia) or in combination with doxycycline (adults in Thailand). Results are pending of arandomized controlled trial, which has recently been completed in Thailand to determine whether TMP-SMX and TMP-SMX plus doxycycline are equivalent. AMC is an alternative for patients with intolerance to TMPSMX and is first-line therapy for children and pregnant women in Thailand, but is associated with an increased risk of relapse compared with TMP-SMX-based therapies. ${ }^{33}$

Pharmacodynamic and pharmacokinetic modelling indicate that the recommended AMC dose should be $20 / 5 \mathrm{mg} / \mathrm{kg}$ every 8 h. ${ }^{99}$ Twice daily doses or formulations containing AMC ratios .4 to 1 are notrecommended. ${ }^{100}$ Chloramphenicol is no longer recommended for the treatment of melioidosis. ${ }^{101}$ Its use in current clinical practice is extremely rare and reserved for neurological infection if ceftazidime, carbapenems or trimethoprim-sulphamethoxazole cannot be used. ${ }^{102}$ In resource-poor settings where parenteral therapy is often difficult to provide or sustain, patients may be treated with oral antimicrobialdrugs. Under such circumstances, the regimen prescribed will be dictated by drug availability and cost, and chloramphenicol may form a component of treatment.

The recommended duration of oral treatment is 3-6 months.For patients with hepatosplenic abscesses, duration of therapy should be guided by time to resolution on serial abdominal imaging. It is not known whether a shorter course of therapy may be adequate for patients with mild and localized disease, such as a single subcutaneous abscess. Monitoring of drug adherence is crucial, as this is probablythe most important factor in determining recurrence.

\section{Treatment recommendations}

\begin{tabular}{|c|c|c|}
\hline $\begin{array}{l}\text { Initial } \\
\text { Parenteral } \\
\text { Therapy }\end{array}$ & $\begin{array}{l}* \text { Ceftazidime } 50 \mathrm{mg} / \mathrm{kg} / \text { dose (up to } 2 \mathrm{~g} \text { ) every } 6-8 \mathrm{~h} \text {, } \\
\text { or } \\
\text { Meropenem } 25 \mathrm{mg} / \mathrm{kg} / \text { dose (up to } 1 \mathrm{~g} \text { ) every } 8 \mathrm{~h}\end{array}$ & $\begin{array}{l}\text { Duration of therapy a minimum of } \\
10-14 \text { days, and } \\
\text { longer }(>/=4 \text { weeks }) \text { for deep- } \\
\text { seated infection }\end{array}$ \\
\hline $\begin{array}{l}\text { Oral } \\
\text { eradication } \\
\text { therapy }\end{array}$ & $\begin{array}{l}\text { TMP/SMX } 8 / 40 \mathrm{mg} / \mathrm{kg} / \text { dose orally BD } \\
*>60 \mathrm{~kg}, 2 \text { X160/800 mg }(960 \mathrm{mg}) \text { tablets BD } \\
* 40-60 \mathrm{~kg}, 3 \times 80 / 400 \mathrm{mg}(480 \mathrm{mg}) \text { tablets BD } \\
*<40 \mathrm{~kg}, 1 \text { X } 160 / 800 \mathrm{mg}(960 \mathrm{mg}) \text { or } 2 \mathrm{X} 80 / 400 \\
\mathrm{mg}(480 \mathrm{mg}) \text { tablets BD } \\
\text { **With or without doxycycline } 2.5 \mathrm{mg} / \mathrm{kg} / \mathrm{dose} \text { (up to } 100 \mathrm{mg} \text { ) } \\
\text { orally BD }\end{array}$ & $\begin{array}{l}\text { Duration at least } 3-6 \text { months, with } \\
\text { actual duration guided by clinical } \\
\text { response to therapy }\end{array}$ \\
\hline
\end{tabular}




\section{How long treatment is required?}

Appropriate treatment is imperative in order to prevent relapse and failure of treatment. Despite appropriate treatment, melioidosis has a higher relapse rate. The average time between discharge from hospital and relapse is of 21 weeks. Treated patients require long-term follow up, as $B$. pseudomalleiremains latent for up to 26 years in the body. ${ }^{103}$ For maintenance therapy, Co-Amoxyclav is a safe and well-tolerated antimicrobial agent (there is some concern that it may be less effective than theconventional regimen of chloramphenicol, co-trimoxazole and doxycycline). The recommended duration for maintenance therapy is of 12 to 20 weeks. ${ }^{104,105}$

It has been shown that $B$. pseudomalleistays intracellularly in the body where it produces biofilms and micro colonies and is sheltered from b-Lactam antimicrobial drugs(bLactam drugs are unable to enter intracellular sites to kill latent $B$. pseudomallei. ${ }^{106}$ It has been suggested that a combination of ciprofloxacin and macrolides is a good alternative regimen since ciprofloxacin penetrates phagocytic cells and achieves intracellular concentrations of several times higher than extracellular concentration and kills $B$. pseudomallei while macrolides could delay or prevent production of glycocalyx ${ }^{107}$

\section{How to prevent?}

Measurers for prevention require prompt cleansing of scrapes, burns, or other open wounds in endemic areas. Persons with diabetes and skin lesions should avoid contact with soil and standing-water in endemic areas. Protective clothing such as rubber boots and gloves during agricultural work can prevent infection through the feet and hands. It is important to maintain safe water through regular disinfection and safe storage of water for both human and animals bred for human consumption. Sewage wastes can attract insects and rodents and encourage the growth of B. pseudomallei. Therefore proper disposal of sewage wastes is essential in endemic areas. As dairy products can contain $B$. pseudomallei it is important that milk is pasteurized before consumption. ${ }^{108}$

There is currently no licensed vaccine available for protection against melioidosis. At present studies are underway to identify possible antigens using lipopolysacchrides of $B$. pseudomallei in mouse models. ${ }^{109}$ Antibodies against $B$. pseudomalleiflagellin reduce the motility of the bacterium and provide protection against melioidosis in animal models. ${ }^{110} \mathrm{~A}$ recent study has shown that quicklime was able to inhibit the growth of $B$. pseudomallei in soil from a rice field. ${ }^{111}$ As our understanding of the disease increases and as we move forward with the studies on the pathogenesis of the disease, new and effective vaccine against melioidosis may become a reality.

\section{Conclusion:}

A high index of suspicion is required in order to diagnose melioidosisin the non-endemic setting. Clinicians should consider the possibility inpatients with a fever who have one or more of the following: a historyof residency in, or travel to a region where melioidosis is endemic; anoccupation or other pursuits associated with contact with soil or waterthat might contain B. pseudomallei(including military personnel whoare on exercise or active service); and the presence of risk factors suchas diabetes mellitus or renal disease. The variability in clinical featuresof infection is such that it is often impossible on clinical grounds todifferentiate between melioidosis and other acute and chronic bacterial infectionsspecially tuberculosis. Confirmation of the diagnosis relies on good practicesfor specimen collection, laboratory investigations.

\section{References:}

1. Whitmore A, Krishnaswami CS. An account of the discovery of a hithertoundescribed infective disease occurring among the population of Rangoon.Indian Med Gazette1912; 47: 262-267.

2. Rimington R A. Melioidosis in Northern Queensland . Med J Aust 1962;1:50-53.

3. Melioidosis: an important emerginginfectious disease - a militaryproblem?ADF Health 2002; 3: 13-21

4. WiersingaWJ ,Currie BJ, Peacock SJ. Melioidosis N Engl J Med 2012;367:1035-44.

5. HosenA.Dadly Bacteria in Gazipursoil.The Daily Star Saturday, July20, 2013

6. Direk L,PeacockSJ. Melioidosis: a clinical overview,British Medical Bulletin 2011; 99: 125-139

7. Cheng AC, Currie BJ. Melioidosis: epidemiology, pathophysiology, and management. ClinMicrobiol Rev 2005; 18:383.

8. Dance DA. Ecology of Burkholderiapseudomallei and the interactions between environmental Burkholderia spp. and human-animal hosts. Acta Trop 2000; 74:159.

9. Dance DB. Melioidosis. Reviews Med Microbiol 1990; 1:143.

10. Dance DA. Melioidosis: the tip of the iceberg? ClinMicrobiol Rev 1991; 4:52.

11. Dance DA. Melioidosis as an emerging global problem.Acta Trop 2000; 74:115

12. Currie BJ, Dance DA, Cheng AC. The global distribution ofBurkholderiapseudomallei and melioidosis: an update. Trans R Soc Trop Med Hyg 2008; 102 Suppl 1:S1. 
13. Punyagupta S. Melioidosis. Review of 686 cases and presentation of a new clinical classification. In: Melioidosis, Punyagupta S, Sirisanthana T, Stapatayavong B (Eds), Bangkok Medical Publisher, Bangkok 1989.

14. Chaowagul W, White NJ, Dance DA, et al. Melioidosis: a major cause of community- acquired septicemia in northeastern Thailand. J Infect Dis 1989; 159:890.

15. Vuddhakul V, Tharavichitkul P, Na-Ngam N, et al. Epidemiology of Burkholderiapseudomalleiin Thailand. Am J Trop Med Hyg 1999; 60:458.

16. Leelarasamee A. Melioidosis in Southeast Asia.Acta Trop 2000; 74:129.

17. Puthucheary SD, Lin HP, Yap PK. Acute septicaemic melioidosis: a report of seven cases. Trop Geogr Med 1981; 33:19.

18. Puthucheary SD, Parasakthi N, Lee MK. Septicaemic melioidosis: a review of 50 cases from Malaysia. Trans R Soc Trop Med Hyg 1992; 86:683.

19. Vadivelu J, Puthucheary SD, Mifsud A, et al. Ribotyping and DNA macrorestriction analysis of isolates of Burkholderiapseudomalleifrom cases of melioidosis in Malaysia. Trans R Soc Trop Med Hyg 1997; 91:358.

20. Hassan MR, PaniSP, Peng NP, et al. Incidence, risk factors and clinical epidemiology of melioidosis: a complex socioecological emerging infectious disease in the AlorSetar region of Kedah, Malaysia. BMC Infect Dis 2010; 10:302.

21. Chan KW, JayaratnamFJ, Teo SK. Acute septicaemic melioidosis. A report of three fatal cases. Singapore Med J $1985 ; 26: 382$.

22. Tan AL, Ang BS, OngYY. Melioidosis: epidemiology and antibiogram of cases in Singapore. Singapore Med J 1990; $31: 335$.

23. Yap EH, Chan YC, GohKT, et al. Sudden unexplained death syndrome - a new manifestation in melioidosis? Epidemiol Infect 1991; 107:577.

24. Yap EH, Thong TW, Tan AL, et al. Comparison of Pseudomonas pseudomalleifrom humans, animals, soil and water by restriction endonuclease analysis. Singapore Med J 1995; 36:60.

25. Singapore Committee on Epidemic Diseases: Melioidosis in Singapore. Epidemiological News Bulletin 1995; 21:69.

26. Lim MK, Tan EH, Soh CS, Chang TL. Burkholderiapseudomalleiinfection in the Singapore Armed Forces from 1987 to 1994 - an epidemiological review. Ann Acad Med Singapore 1997; 26:13.

27. Lo TJ, AngLW, James L, Goh KT. Melioidosis in a tropical city state, Singapore. Emerg Infect Dis 2009; 15:1645.
28. Currie BJ, Fisher DA, Howard DM, et al. The epidemiology of melioidosis in Australia and Papua New Guinea.Acta Trop 2000; 74:121.

29. Currie BJ, Fisher DA, Howard DM, et al. Endemic melioidosis in tropical northern Australia: a 10-year prospective study and review of the literature. Clin Infect Dis 2000; 31:981.

30. Malczewski AB, Oman KM, Norton RE, Ketheesan N. Clinical presentation of melioidosis in Queensland, Australia. Trans R Soc Trop Med Hyg 2005; 99:856.

31. Warner J, Learoyd D, Pelowa D, et al. Melioidosis in the Western Province of Papua New Guinea. In: Annual Scientific Meeting, Medical Society of Papua New Guinea, Port Moresby 1998 .

32. Le Hello S, Currie BJ, Godoy D, et al. Melioidosis in New Caledonia. Emerg Infect Dis 2005; 11:1607.

33. Limmathurotsakul D, Wongratanacheewin S, Teerawattanasook N, et al. Increasing incidence of human melioidosis in Northeast Thailand. Am J Trop Med Hyg $2010 ; 82: 1113$.

34. Saravu K, Mukhopadhyay C, Vishwanath S, et al. Melioidosis in southern India: epidemiological and clinical profile. Southeast Asian J Trop Med Public Health 2010; 41:401.

35. Currie BJ, Ward L, Cheng AC. The epidemiology and clinical spectrum of melioidosis: 540 cases from the 20 year Darwin prospective study. PLoSNegl Trop Dis 2010; 4:e900.

36. Leelarasamee A, Bovornkitti S. Melioidosis: Review and update. Rev Infect Dis 1989;11:413-25.

37. Vadivellu J, Puthucheary SD, GendehGS, Parasakthi N. Serodiagnosis of melioidosis in Malaysia. Singpore Med J 1995;36:299-302.

38. Miralles IS, MacielMdo C, Angelo MR, et al. Burkholderiapseudomallei: a case report of a human infection in Ceará, Brazil. Rev Inst Med Trop Sao Paulo 2004; 46:51.

39. Rolim DB, Vilar DC, Sousa AQ, et al. Melioidosis, northeastern Brazil. Emerg Infect Dis 2005; 11:1458.

40. Inglis TJ, Rolim DB, Sousa Ade Q. Melioidosis in the Americas. Am J Trop Med Hyg 2006; 75:947.

41. Dance DA, Smith MD, Aucken HM, Pitt TL. Imported melioidosis cases in England and Wales. Lancet 1999;353:208.

42. Chierakul W, Wuthiekanun V, ChaowagulW, et al. Disease severity and outcomeof melioidosis in HIV coinfectedindividuals.Am J Trop Med Hyg 2005;73:1165-6.

43. WiersingaWJ, van der Poll T, WhiteNJ, Day NP, Peacock SJ. Melioidosis: insights into the pathogenicity of Burkholderiapseudomallei. Nat Rev Microbiol2006;4: 272-82. 
44. Tumapa S, Holden MT, VesaratchavestM, et al. Burkholderiapseudomallei genomeplasticity associated with genomicisland variation. BMC Genomics 2008;9:190.

45. SimSH, Yu Y, Lin CH, et al. The coreand accessory genomes of Burkholderiapseudomallei: implications for humanmelioidosis. PLoSPathog 2008;4(10):e1000178.

46. Price EP, Hornstra HM, LimmathurotsakulD, et al. Withinhost evolution ofBurkholderiapseudomallei in four casesof acute melioidosis. PLoSPathog 2010;6(1):e1000725.

47. Kang G, Rajan DP, Ramakrishna BS, Auken HM, Dance DA. Melioidosis in India. Lancet 1996; 347:1565-6.

48. Cheng AC, Currie BI. Melioidosis: Epidemiology, Pathophysiology and Management. Clinical Microbiology Reviews. 2005; 18: 383-416. doi:10.1128/CMR.18.2.383416.2005

49. Dance DAB. Melioidosis: Distribution and epidemiology. First international symposium on Melioidosis in Kuala Lumpur Malaysia 1994;7-8.

50. Wongwanich S, Chotanachan P, Kondo E, Kanai K. Multifactorial pathogenic mechanisms of Burkholderiapseudomallei as suggested from comparison with Burkholderiacepacia . Southeast Asian J Trop Med Public Health 1996;27:111-8.

51. Dance DA, Wuthiekanun V, Chaowagul W, Suputtamongkol Y, White NJ. Development of resistance to ceftazidime and co-amoxyclav in Pseudomonas pseudomallei. J AntimicrobChemother 1991;28:321-4.

52. Moore RA, DeShazer D, Reckseidler S, Weissman A, Woods DE. Efflux-Mediated Aminoglycoside and Macrolide Resistance in Burkholderiapseudomallei .Antimicrob Agents Chemother 1999;43:465-70.

53. Tribuddharat C, Moore RA, Baker P, Woods DE. Burkholderiapseudomallei class a beta-lactamase mutations that confer selective resistance against ceftazidime or clavulanic acid inhibition. Antimicrob Agents Chemother 2003;47:2082-7.

54. Howe C, Sampath A, Spotnitz M. The Pseudomallei group: A review. J Infect Dis 1971;124:598-606.

55. Holland DJ, Wesley A, Drinkovic D, Currie BJ. Cystic Fibrosis and Burkholderiapseudomallei Infection: An Emerging Problem? Clin Infect Dis 2002;35:138-40

56. Abbink FC, OrendiJM, de Beaufort AJ. Mother to child transmission of Burkholderiapseudomallei. N Eng J Med 2001;344:1171-2.

57. McCormick JB, Sexton DJ, McMurray JG, Carey E, Hayes P, Feldman RA. Human-to-human transmission of Pseudomonas pseudomallei . Ann Intern Med 1975;83:512-3

58. Jones AL, BeveridgeTJ, Woods DE. Intracellular survival of Burkholderiapseudomallei. Infect Immun 1996;64:782-90.
59. Kespichayawattana W, Rattanachetkul S, Wanun T, Utaisincharoen P, Sirisinha S. Burkholderiapseudomallei Induces Cell Fusion and Actin-Associated Membrane Protrusion: a Possible Mechanism for Cell-to-Cell Spreading. Infect Immun 2000;68:5377-84.

60. Nonereitbach K, Rottner K, Klocke S, Rohde M, Jenzora A, Wehland $\mathrm{J}$, et al. Actin-based motility of Burkholderiapseudomalle i involves the Arp 2/3 complex, but not N-WASP and Ena/VASP proteins. Cell Microbiol 2003; 5: 385-93.

61. Stevens MP, Galyov EE. Exploitation of host cells byBurkholderiapseudomallei .Int J Med Microbiol 2004;293:549-55.

62. Ghosh P. Process of Protein Transport by the Type III Secretion System. MicrobiolMolBiol Rev 2004;68:771-95.

63. Harley VS, Dance DA, Drasar BS, Tovey G. Effects of Burkholderiapseudomallei and other Burkholderiaspecies on eukaryotic cells in tissue culture. Microbios 1998; 96: 71-93.

64. Miyagi K, Kawakami K, Saito A. Role of reactive nitrogen and oxygen intermediates in gamma interferon-stimulated murine macrophage bactericidal activity against Burkholderiapseudomallei. Infect Immun 1997;65:4108-13.

65. Utaisincharoen P, Anuntagool N, Limposuwan K, Chaisuriya $\mathrm{P}$, Sirisinha S. Involvement of beta interferon in enhancing inducible nitric oxide synthase production and antimicrobial activity of Burkholderiapseudomallei -infected macrophages. Infect Immun 2003;71:3053-7.

66. Raja NS. Localized melioidosis. J Pak Med Assoc 2003; 53: 373-4

67. Koszyca B, Currie BJ, Blumbergs PC. The neuropathology of melioidosis: two cases and a review of the literature. ClinNeuropathol 2004;23:195-203

68. Schwarzmaier A, Riezinger-Geppert F, Schober G, Karnik $\mathrm{R}$, Valentin A. Fulminant septic melioidosis after a vacation in Thailand. Wien KlinWochenschr 2000;112:892-5

69. Currie B, Howard D, Nguyen VT, Withnall K, Merianos A. The 1990-1991 outbreak of melioidosis in the Northern Territory of Australia: clinical aspects. Southeast Asian J Trop Med Public Health 1993;24:436-43.

70. Johnson AB, Ali N. Reactivation of latent melioidosis. Postgrad Med J 1990;66:732-3.

71. Thummakul T, Wilde H, Tantawichien T. Melioidosis, an environmental and occupational hazard in Thailand. Mil Med 1999;164:658-62.

72. Kiertiburanakul S, Sungkanuparph S, Kositchiwat S, Vorachit M. Burkholderiapseudomalleiabscess in unsual site. J Postgrad Med 2002;48:124-6. 
73. Lim WK, GurdeepGS, Norain K. Melioidosis of the head and neck. Med J Malaysia 2001;56:471-7.

74. Wong PK, Ng PH. Melioidosis presenting with orbital cellulitis. Singapore Med J 1996;37:220-1.

75. Low JG, QuekAM, Sin YK, Ang BS. Mycotic aneurysm due to Burkholderiapseudomalleiinfection: case reports and literature review. Clin Infect Dis 2005;40:193-8.

76. Majid AA. Successful surgical management of a case of pulmonary and pericardial melioidosis. Aust N Z J Surg 1990;60:139-41.

77. Sirikulchayanonta V, Subhadrabandhu T. Melioidosis. Another etiology of granulomatous osteomyelitis. Report of 2 cases. ClinOrthop 1994;308:183-6.

78. Badsha H, Edwards CJ, ChngHH. Melioidosis in systemic lupus erythematosus: the importance of early diagnosis and treatment in patients from endemic areas.Lupus 2001;10: $821-3$

79. Tan JK, Yip SK, Png DJ, Moorthy P. Primary melioidotic prostatic abscess: presentation, diagnosis and management. ANZ J Surg 2002;72:408-10.

80. Lath R, Rajshekhar V, George V. Brain abscess as the presenting feature of melioidosis. Br J Neurosurg 1998;12:170-2.

81. Currie BJ, Fisher DA, Howard DM, Burrow JN. Neurological melioidosis. Acta Trop 2000;74:145-51.

82. Cheng AC, Obrien M, JacupsSP, Anstey NM, Currie BJ. Creactive protein in the diagnosis of melioidosis. Am J Trop Med Hyg 2004;70:580-2.

83. Anuntagool N, Rugdech P, Sirisinha S. Identification of specific antigens of Pseudomonas pseudomalleiand their efficacies for diagnosis of melioidosis.JClin Microbiol1993;31:12326.

84. Lowe P, Engler C, Norton R. Comparison of automated and nonautomated systems for identification of Burkholderiapseudomallei . J ClinMicrobiol 2002;40: 4625-7.

85. InglisTJ, Chiang D, Lee GS, Chor-Kiang L. Potential misidentification of B. pseudomalleiby API 20NE. Pathology 1998;30:62-4.

86. Ashdown LR. An improved screening technique for isolation of Pseudomonas pseudomallei from clinical specimens. Pathology 1979;11:293-7.

87. Howard K, InglisTJ. Novel selective medium for isolation of Burkholderiapseudomallei . J ClinMicrobiol 2003;41: 3312-6.

88. Appassakij H, Silpapojakul KR, Wansit R, Pornpatkul M. Diagnositic value of the the indirect haemagglutination test for melioidosis. Am J Trop Med Hyg 1990;42:248-53.
89. Ashdown LR, Johnson RW, Koehler JM, Cooney CA. Enzyme-linked immunosorbent assay for the diagnosis of clinical and subclinical melioidosis. J Infect Dis 1989;160: 253-60.

90. Rattanathongkom A, SermswanRW, Wongratanacheewin S. Detection of Burkholderiapseudomallei in blood samples using polymerase chain reaction.MolCell Probes 1997;11:2531.

91. Kunakorn M, Raksakait K, Sethaudom C, SermswanRW, Dharakul T. Comparison of three PCR primer sets for diagnosis of septicemic melioidosis. Acta Trop 2000;74: 247-51.

92. Harris P, Engler C, Norton R. Comparativein vitro susceptibility of Burkholderia pseudomallei to doripenem, ertapenem,tigecycline and moxifloxacin.Int J Antimicrob Agents 2011;37:547-9.

93. Trunck LA, Propst KL, WuthiekanunV, et al. Molecular basis of rare aminoglycoside susceptibility and pathogenesis ofBurkholderiapseudomallei clinical isolatesfrom Thailand. PLoSNeg1 Trop Dis2009;3(9):e519.

94. Rholl DA, Papp-Wallace KM, TomarasAP, Vasil ML, Bonomo RA, Schweizer HP. Molecular investigations of PenA-mediatedâ-lactam resistance in Burkholderiapseudomallei. Front Microbiol 2011;2:139.

95. Stephens DP, Fisher DA, Currie BJ. An audit of the use of granulocyte colony-stimulating factor in septic shock. Intern Med J 2002;32:143-8.

96. Cheng AC, Limmathurotsakul D, Chierakul W et al. A randomized controlled trial of granulocytecolony-stimulating factor for the treatment of severe sepsis due to melioidosis in Thailand. Clin Infect Dis 2007;45:308-14.

97. Chierakul W, Anunnatsiri S, Short JM et al. Two randomized controlled trials of ceftazidime alone versus ceftazidime in combination with trimethoprim-sulfamethoxazole for the treatment of severe melioidosis. Clin Infect Dis 2005; 41: 1105-13.

98. Morse LP, Moller CC, Harvey E et al. Prostatic abscess due to Burkholderiapseudomallei: 81 cases from a 19 -year prospective melioidosis study. J Urol 2009;182:542-7; discussion 47.

99. Chierakul W, Wangboonskul J, Singtoroj T et al. Pharmacokinetic and pharmacodynamic assessment of coamoxiclav in the treatment of melioidosis. J Antimicrob Chemother 2006;58:1215-20.

100. Cheng AC, Chierakul W, Chaowagul W et al. Consensus guidelines for dosing of amoxicillinclavulanatein melioidosis. Am J Trop Med Hyg 2008;78:208-9.

101. Chaowagul W, Chierakul W, Simpson AJ et al. Open-label randomized trial of oral trimethoprim-sulfamethoxazole, 
doxycycline, and chloramphenicol compared with trimethoprim-sulfamethoxazole and doxycycline for maintenance therapy of melioidosis. Antimicrob Agents Chemother 2005;49:4020-5.

102. Limmathurotsakul D, Chaowagul W, Wongsrikaew $\mathrm{P}$ et al. Variable presentation of neurologicalmelioidosis in Northeast Thailand. Am J Trop Med Hyg 2007;77:118-20.

103. Rajchanuvong A, Chaowagul W, Suputtamongkol Y, Smith MD, Dance DA, White NJ. Aprospective comparison of co-amoxiclav and the combination of chloramphenicol, doxycycline and cotimoxazole for the oral treatment of melioidosis. Trans R Soc Trop Med Hyg 1995;89:546-9.

104. Chetchotisakd P, Chaowagul W, Mootsikapun P, Budhsarawong D, Thinkamrop B. Maintenance therapy of melioidosis with ciprofloxacin plus azithromycin compared with cotrimoxazole plus doxycycline. Am J Trop Med Hyg 2001;64:24-7.

105. Pruksachartvuthi S, Aswapokee N, Thankerngpol K. Survival of Pseudomonas pseudomallei in human phagocytes. J Med Microbiol 1990;31:109-14.
106. Chateau MT, Caravano R. Rapid fluorometric measurement of the intra-cellular concentration of ciprofloxacin in mouse peritoneal macrophages. J AntimicrobChemother 1993;31:281-7.

107. Vorachit M, Chongtrakool P, Arkomsean S, Boonsong S. Antimicrobial resistance in Burkholderiapseudomallei . ActaTropica 2000;74:139-44.

108. Choy JL, Mayo M, Janmaat A, Currie BJ. Animal melioidosis in Australia. Acta Trop 2000;74:153-8.

109. Nelson M, Prior JL, Lever MS, Jones HE, Atkins TP, TitballRW. Evaluation of lipopolysaccharide and capsular polysaccharide as subunit vaccines against experimental melioidosis. J Med Microbiol 2004;53:1177-82.

110. Brett PJ, Mah DC, Woods DE. Isolation and characterization of Pseudomonas pseudomalleiflagellin proteins. Infect Immun 1994;62:1914-9.

111. Nangam N, Angkititakul S, Noimay P, Thamlikitkul V. The effect of quicklime (calcium oxide) as an inhibitor of Burkholderiapseudomallei. Trans R Soc Trop Med Hyg 2004; 98:337-41. 